\title{
Analysis of stress field during Submerged Arc Weld surfacing
}

\author{
J. Winczek ${ }^{1}$, K. Makles ${ }^{1}$, M. Gucwa ${ }^{1}$, R. Gnatowska ${ }^{1}$ and M. Hatala ${ }^{2}$ \\ \{winczek@gmail.com,krzymakles@gmail.com,mgucwa@spaw.pcz.pl, \\ rgnatowska@gmail.com, michal.hatala@tuke.sk\}
Faculty of Mechanical Engineering and Computer Science, Czestochowa University of Technology, Dabrowskiego 69, 42-201 Czestochowa, Poland ${ }^{1}$
Faculty of Manufacturing Technologies, Technical University of Kosice with a seat in Prešov, Bayerova 1, 08001 Prešov, Slovakia $^{2}$

\begin{abstract}
In work the model of stress calculation and analysis of stress field during single-pass SAW (Submerged Arc Welding) surfacing have been presented. In the temperature field solution, influence heat of melted electrode and heat of direct impact of electric arc have been taken into consideration. The phase change kinetics according to the laws of Johnson-Mehl-Avrami-Kolmogorov and Koistinen-Marburger were determined. The temperatures of the beginning and the end of the changes were determined by the $A_{c 1}$ and $A_{c 3}$ temperatures during heating and on the basis of the timetemperature-transformation welding diagram for cooling. The stress state of thermal loaded flat has been described assuming planar section hypothesis and simple Hooke's law and using integral equations of stress equilibrium. The stress-strain curves were modeled as the curves of the mixture of individual material phases depending on temperature. The analysis of stress state has been presented for SAW surfacing S355 steel plate.
\end{abstract}

Keywords: submerged arc welding, weld surfacing, rebuilding, modelling, temperature field, phase transformations, stresses.

\section{Introduction}

In modeling of thermo-mechanical phenomena in welding processes it is necessary to take into account the action of the temperature field and the impact of phase transformations. Temperature changes cause thermal strains, and depending on the temperature and type of material, they lead to phase transformations. The phase changes effect is structure changes and related to them material property changes. The change of the structure type is accompanied by structural strain associated with different densities of austenite, ferrite, bainite, martensite and pearlite. Finally, determining the magnitude of thermal strains and strains from phase transformations enable the determination of temporary and residual stresses. 


\section{Temperature field}

For the theoretical determination of the temperature field in welding processes, two calculation methods are used: analytical (semi-analytical) [1 - 5] and numerical [6-11]. Solutions are developed for specific welding methods and for a particular type of connection. Most solutions use a single-distributed source model. In this work, in the calculation of the temperature field the bimodal heat source model has been adopted [12]. The heat density distribution of this source is the sum of the heat distributions caused by the following models: the heat source model of melted electrode and the heat source model of heat induced by direct action of electric arc. The total amount of heat generated in the process is the sum of heat transferred through the molten electrode and emitted by an electric arc, which can be recorded as follows:

$$
T(x, y, z, t)-T_{0}=T_{a}(x, y, z, t)+T_{w}(x, y, z, t)
$$

where: $T_{a}(x, y, z, t)$ - the temperature increase caused by heat emitted by an electric arc, $T_{w}(x, y, z, t)$ - the temperature increase caused by the heat transferred through molten electrode to reinforcement.

A detailed description of the bimodal heat source model and the analytical differential solution for the heat conduction equation, which is the basis for the description of the temperature field, is contained in [13].

\section{Phase transformation kinetics}

In quantification, the progress of phase transformations in steel during thermal welding cycle is described by Johnson-Mehl-Avrami's and Kolmogorov's (JMAK) formula [14, 15] for diffusive transformation and Koistinen-Marburger (KM) rule for martensitic transformation [16]. During heating, the phase transformations of the initial structure into austenite occur after exceeding the critical temperature $A_{l}$, and end at the temperature $A_{3}$. The volume participation of austenite $\varphi_{A}$ created during heating is the temperature of the process in relation to the temperatures $A_{1}$ and $A_{3}$. Amount of created austenite is defined by JMAK rule [14]:

$$
\varphi_{A}(T)=\sum_{j} \varphi_{j}^{0}\left(1-\exp \left(-b_{j}(T) t^{n_{j}(T)}\right)\right)
$$

where $\varphi_{j}^{0}$ denotes initial volumetric share $(j \equiv F-$ ferrite, $j \equiv P$ - pearlite, $j \equiv B$ - bainite). The constant $b_{j}$ and $n_{j}$ are determined depending on the values $A_{l}$ and $A_{3}$ :

$$
n_{j}=\frac{\ln (\ln (0.99))}{\ln \left(A_{1} / A_{3}\right)}, b_{j}=\frac{0.01 n_{i}}{A_{1}}
$$

To describe the kinetics of the transformation of austenite into ferrite, perlite or bainite during cooling, the principle of additivity can be applied, and then the volume fraction of the newly formed phase $\varphi_{j}$ is expressed by [15]: 


$$
\begin{gathered}
\varphi_{j}=\varphi_{A} \varphi_{j}^{\max }\left(1-\exp \left(-b_{j} T^{n_{j}}\right)\right)+\varphi_{j}^{0} \\
n_{j}=\frac{\ln \left(\ln \left(1-\varphi_{j}^{s}\right) / \ln \left(1-\varphi_{j}^{f}\right)\right)}{\ln \left(T_{j}^{s} / T_{j}^{f}\right)}, b_{j}=\frac{n_{j}\left(1-\varphi_{j}^{f}\right)}{T_{j}^{s}} \\
\frac{\varphi_{j}^{s}}{\varphi_{j}^{\max }}=0.01, \frac{\varphi_{j}^{f}}{\varphi_{j}^{\max }}=0.99
\end{gathered}
$$

where: $\varphi_{j}^{0}$ is volume share of $j$-th structural component, which has not been transformed during the austenitization, $T_{j}^{s}=T_{j}^{s}\left(v_{8 / 5}\right)$ and $T_{j}^{f}=T_{j}^{f}\left(v_{8 / 5}\right)$ are respectively begin and end temperature of phase transformation of $j$ component.

The volume share of martensite $\varphi_{M}$ formed from austenite for process temperature $T$ below $M_{s}$ (initial temperature of martensitic transformation) is calculated using the KoistinenMarburger rule [16]:

$$
\begin{gathered}
\varphi_{M}(T)=\varphi_{A} \varphi_{M}^{\max }\left\{1-\exp \left[-\mu\left(M_{s}-T\right)\right]\right\} \\
\mu=\ln \left(\varphi_{M}^{\min }\right) /\left(M_{s}-M_{f}\right)
\end{gathered}
$$

where: $M_{f}$ - temperature of the end of martensitic transformation, $\varphi_{M}^{\min }=0.1$.

\section{Thermal and structural strains}

Total strain during single-pass surfacing is the sum of thermal and structural strains during heating $\left(\varepsilon^{H}\right)$ and cooling $\left(\varepsilon^{C}\right)$ :

$$
\varepsilon(x, y, z, t)=\varepsilon^{H}+\varepsilon^{C}
$$

Then strains during heating is equal to:

$$
\begin{aligned}
\varepsilon^{H} & =\sum_{i=A, P, F, B, M}\left\{\alpha_{i} \varphi_{i 0}\left(T-T_{0}\right) H\left(T_{A_{1}}-T\right)+\alpha_{i} \varphi_{i}\left(T-T_{A_{1}}\right) H\left(T_{A_{3}}-T\right) H\left(T-T_{A_{1}}\right)+\right. \\
& \left.+\alpha_{A}\left(T-T_{A_{3}}\right) H\left(T-T_{A_{3}}\right)+\varphi_{i} \gamma_{i A}\right\}
\end{aligned}
$$

where: $\gamma_{i A}$ - structural strain of $i$-th structure in austenite, $T_{0}$ - initial temperature, $\alpha_{i}$ - linear thermal expansion coefficient of $i$-th structure, and $H(x)$ is the function defined as follows:

$$
H(x)=\left\{\begin{array}{l}
1 \quad \text { for } x>0 \\
0,5 \text { for } x=0 \\
0 \quad \text { for } x<0
\end{array}\right.
$$


During cooling, the strain can be described by the relation:

$$
\begin{aligned}
\varepsilon^{C} & =\alpha_{A}\left(T-T_{S O L}\right) H\left(T-T_{s}\right)+\alpha_{A}\left(T_{s}-T_{S O L}\right) H\left(T_{s}-T\right)+ \\
& +\sum_{j=A, P, F, B, M} \alpha_{i} \varphi_{i}\left(T-T_{s i}\right) H\left(T_{s i}-T\right)+\sum_{j=P, F, B, M} \varphi_{i} \gamma_{A i}
\end{aligned}
$$

where $T_{S O L}$ - solidus temperature, $T_{s}$ - initial of phase transformation, $\gamma_{A i}$ and $T_{s j}$ - austenite phase transformation strain and initial temperature of its transformation in $j$-th structure, $\gamma_{A j}-$ structural strain of austenite in $j$-th hardening structure.

From the condition of preserving the solid state of the material:

$$
\varepsilon(x, y, z, t)=0 \quad \text { for } \quad T>T_{S O L}
$$

\section{Model of stress calculation}

A thermally and mechanically loaded element is considered. The dimensions of the crosssection of the element are significantly small compared to its length. The cross-section shape of the element is unchanged over its entire length. In consideration of the stress state, the internal forces $N=N(x)$ and $M_{y}=M_{y}(x)$ were taken into account. It has been assumed that there is no $M_{x}=M_{x}(x)$ load and transverse forces $T_{y}=T_{y}(x), T_{z}=T_{z}(x)$ are omitted as negligibly small. The temperature field is symmetrical with respect to the $x$ axis, which is characteristic for the welding process. One-dimensional stress state is considered in the crosssection of the element (Fig. 1). Because the thermal load is symmetrical with respect to the $x$ axis, the stress state is also symmetrical with respect to this axis: $\sigma_{x}=\sigma_{x}(x, z, t)=\sigma_{x}(x,-y, z, t)$.

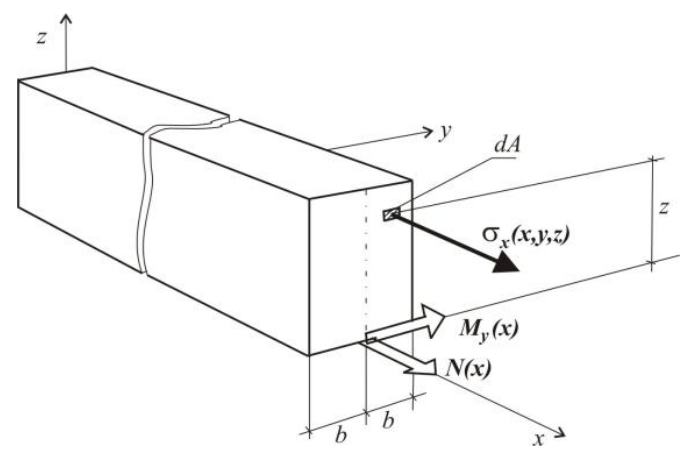

Fig. 1. Scheme of rod subjected to mechanical and thermal loads.

The stress formula for the above described load condition was derived assuming the hypothesis of a planar cross-section (for moderately small strains) and using Cauchy's relations. According to the technical theory of bent bars, in considered case of stress state differential equations of equilibrium were not used.

Instead, integral conditions of equilibrium using simple Hooke's law $\sigma_{x}=E \varepsilon_{x}$ are applied [17]. For a heterogeneous material and modulus of longitudinal elasticity dependent on 
temperature, the stress in the cross-section subjected to thermal-mechanical loads described above will be expressed as follows:

$$
\begin{aligned}
\sigma= & \frac{E}{A^{E} J_{y}^{E}-\left(S_{y}^{E}\right)^{2}}\left\{J_{y}^{E}\left(N(x)+N^{T}\right)+S_{y}^{E}\left(M(x)-M_{y}^{T}\right)+\right. \\
& \left.-A^{E}\left(M(x)-M_{y}^{T}\right)+S_{y}^{E}\left(N(x)+N^{T}\right) z\right\}-E \varepsilon_{0}-\alpha E T
\end{aligned}
$$

where:

$$
\begin{gathered}
A^{E}=\int_{(A)} E d A \quad S_{y}^{E}=\int_{(A)} E z d A \quad J_{y}^{E}=\int_{(A)} E z^{2} d A \\
N^{T}=\int_{(A)} \alpha E T d A \quad M_{y}^{T}=\int_{(A)} \alpha E T z d A
\end{gathered}
$$

The stress in the elasto-plastic range was determined by iteration using the elastic solution method with respect to the stretching curves modeled for each cross-section point [18]. The stress-strain curves are modeled as the curves of the mixture of individual structural tensile curves depending on temperature.

\section{Example of calculation}

Calculations of the temporary temperature field for a square steel element with the side length $0,2 \mathrm{~m}$ and thickness of the plate $0,03 \mathrm{~m}$ made from steels $\mathrm{S} 355 \mathrm{~J} 2 \mathrm{G} 3$ have been conducted. Thermal properties of welded subject material and electrode have been determined by $a=8 \cdot 10^{-6} \mathrm{~m}^{2} / \mathrm{s}, C_{p}=670 \mathrm{~J} / \mathrm{kg} \mathrm{K}, \rho=7800 \mathrm{~kg} / \mathrm{m}^{3}$ and $L=268 \mathrm{~kJ} / \mathrm{kg}$.

Numerical simulation has been conducted for the welding heat source of power $3500 \mathrm{~W}$, which corresponds to welding parameters $(U=30 \mathrm{~V}, I=400 \mathrm{~A}, \eta=0,95)$. In calculations there were assumed welding velocity $v=0,007 \mathrm{~m} / \mathrm{s}$, electrode wire diameter $d=3,5 \mathrm{~mm}$, wire feed speed $v_{e}=0,031 \mathrm{~m} / \mathrm{s}$ and bead dimensions $h_{w}=2,5 \mathrm{~mm}$ and $w_{w}=22 \mathrm{~mm}\left(d_{p}=0\right)$. The initial value of temperature of electrode $T_{e}=100{ }^{\circ} \mathrm{C}$ (a temperature of contact tip with the welding head). Computations have been made for middle cross-section of the surfaced element.

In Figure 2 maximum temperature distribution in cross section has been presented. The calculated isotherm $1493{ }^{\circ} \mathrm{C}$ determines the fusion line and isotherms $A_{3}$ and $A_{l}$ determine the partial and full austenitization zones (Fig. 3). In the Figure 3, the selected cross section points were marked, for which an stress analysis were performed. The temperatures $A_{3}=920{ }^{\circ} \mathrm{C}$ and $A_{1}=748{ }^{\circ} \mathrm{C}$ have been calculated taking into account the effect of heating rate on these temperatures [19].

The phase transformations kinetics during heating is limited by the temperatures $A_{l}$ of the beginning and $A_{3}$ the end of the austenite transformation, while the progress of phase transformations during cooling was determined on the basis of TTT-welding diagram for S355 steel shown in Fig. 4 [20]. 


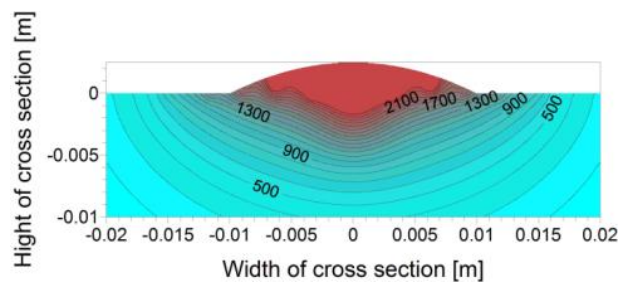

Fig. 2. Maximum temperature field.

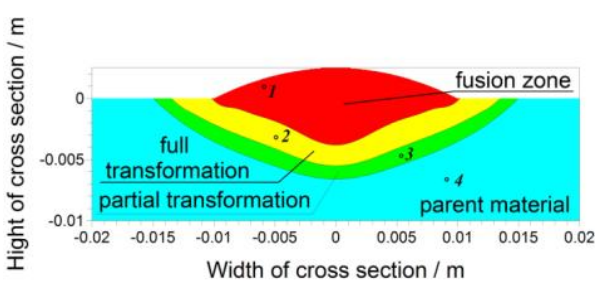

Fig. 3. Calculated heat affected zones.

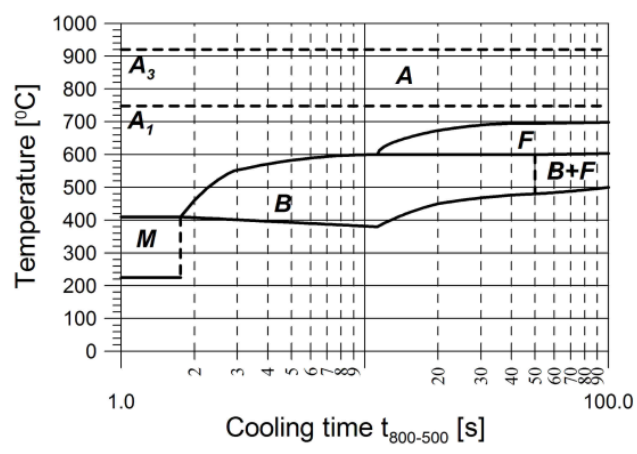

Fig. 4. TTT-welding diagram for S355 steel.

Table 1. Structural strains $(\gamma)$ and thermal $(\alpha)$ expansion coefficients of phases [20]

\begin{tabular}{|l|l|l|l|}
\hline & \multicolumn{1}{|c|}{$\alpha\left[1 /{ }^{\circ} \mathrm{C}\right]$} & & \multicolumn{1}{c|}{$\gamma$} \\
\hline Austenite & $2.178 \cdot 10^{-5}$ & $\gamma_{\mathrm{F}, \mathrm{P}, \mathrm{S} \rightarrow \mathrm{A}}$ & $1.986 \cdot 10^{-3}$ \\
\hline Ferrite & $1.534 \cdot 10^{-5}$ & $\gamma_{\mathrm{B} \rightarrow \mathrm{A}}$ & $1.440 \cdot 10^{-3}$ \\
\hline Pearlite & $1.534 \cdot 10^{-5}$ & $\gamma_{\mathrm{A} \rightarrow \mathrm{F}, \mathrm{P}}$ & $3.055 \cdot 10^{-3}$ \\
\hline Bainite & $1.171 \cdot 10^{-5}$ & $\gamma_{\mathrm{A} \rightarrow \mathrm{B}}$ & $4.0 \cdot 10^{-3}$ \\
\hline Martensite & $1.36 \cdot 10^{-5}$ & & \\
\hline
\end{tabular}

In strain calculations there were assumed thermal linear expansion coefficients of particular structural elements and structural strains (Tab. 1) determined on the basis of the author's own dilatometric research [21].

Tensile curves of ferrite and pearlite are assumed on the basis of works [22, 23]. In case of austenite, bainite and martensite on the basis of data from works [24, 25] tensile curves are determined according to Swift law [26].

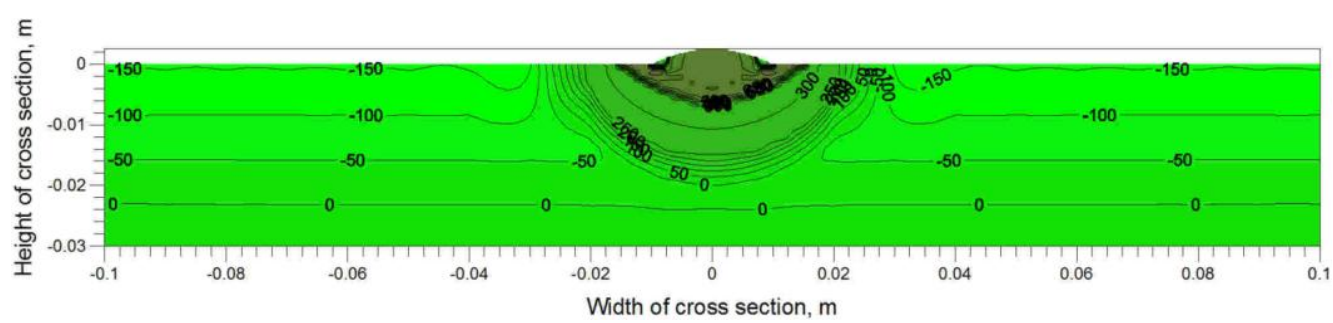

Fig. 5. Distribution of normal residual stresses after weld surfacing in the cross section of plate. 


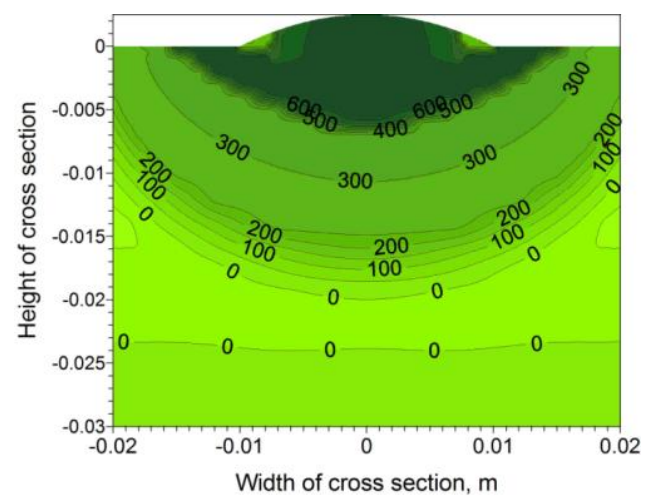

Fig. 6. Distribution on normal residual stresses in the middle part-area of cross section of plate.

Distribution of normal residual stresses distribution in the whole cross-section of the weld surface flat has been presented in Fig. 5, while for the middle cross section at the distance between $-0.02 \mathrm{~m}$ and $0.02 \mathrm{~m}$ from the weld axis has been presented in Fig. 6 .

The stress history at selected points of cross section (cf. Fig 3). has been presented in Figs. 7 - 8. At point 1 from reinforcement area (Fig. 7a), the stresses are zero to solidification the weld material. When point $l$ is already in solid state, due to shrinkage caused by further cooling, tensile stresses increase. Structural strains accompanying the phase transformations create compressive stresses. Further cooling of the material causes the material to undergo tensile stress, which after completely cooling the stress reaches $618 \mathrm{MPa}$.

a)

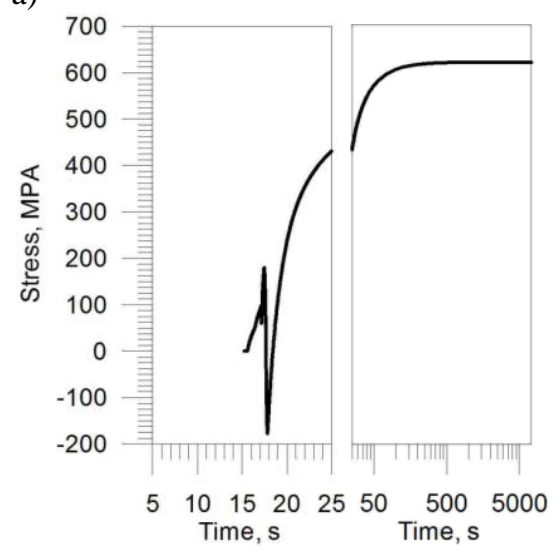

b)

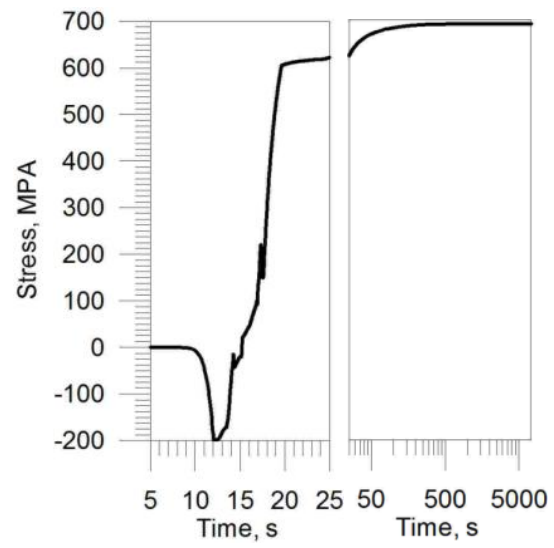

Fig. 7. Normal stresses at points 1 (a) and 2 (b) during weld surfacing.

At point 2 (Fig. 7b) located outside the fusion zone, during the welding thermal cycle full phase transformation takes place. During heating, the thermal expansion of the material leads to the development of compressive stresses. During cooling, the compressive stress decreases and then the tensile stresses increase. Phase transformations are shown in the form of the characteristic breakdowns of graph (decreases in the value of tensile stresses). Further cooling of the material causes increases tensile stress, which after completely cooling stress reaches 
the level of almost $700 \mathrm{MPa}$. Maximum temperature at point 3 (Fig. 8a) did not exceed $A_{3}$, therefore a partial transformation occurs at this point. Similarly to point 2 , during heating, the thermal expansion of the material leads to the development of compressive stresses and next during cooling the compressive stress decreases and then the tensile stresses increase. Decreases in the value of tensile stresses induced by phase transformations (smaller structural strains) are visible in the graph in the form of smaller breakdowns. It causes that after completely cooling the stress reaches the level of over $600 \mathrm{MPa}$. The maximum temperature in point 4 (Fig. 8b) did not exceed the temperature $A_{l}$, so there was no phase transformation at this point. The stress state is determined by the thermal expansion of the material, the yield stress depending on the temperature and stress equilibrium of the cross-section. During the heating, the compressive stresses increase, and during cooling they change the mark and go into tensile stresses reaching $318 \mathrm{MPa}$.

a)

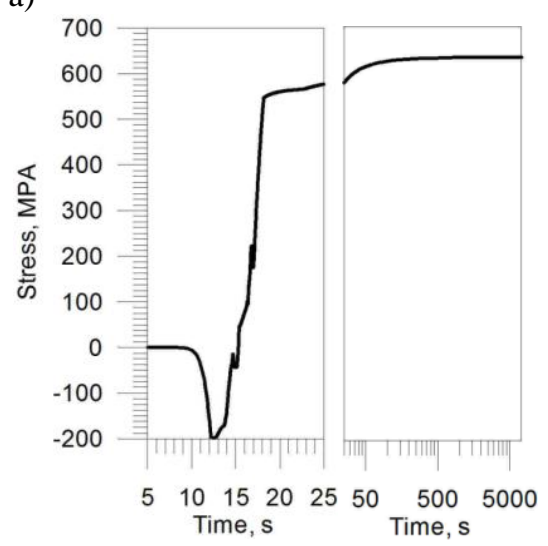

b)

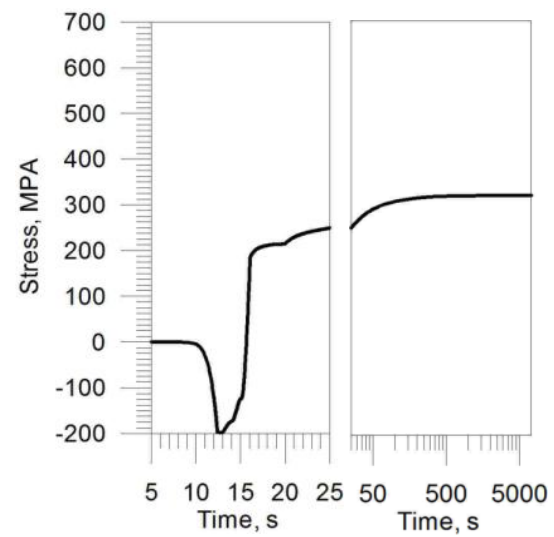

Fig. 9. Normal stresses at points 3 (a) and 4 (b) during weld surfacing.

\section{Conclusion}

Presented model allows analysing and interpreting the influence of temperature field and phase transformations on strains and stresses caused by welding process using SAW method. Calculated temperature field, volume fractions of phases and stresses in longitudinally surfaced elements enable:

(i) determination of heat affected zone, including areas of full and partial phase transformation, as well fusion zone,

(ii) analysis o welding thermal cycle, volume share of structure, strain and stress in selected point of surfaced element,

(iii) analysis of stresses during weld surfacing and residual stresses distribution in any crosssection after Submerged Arc Weld surfacing.

Calculated residual stresses have a distribution confirmed by experimental research and numerical calculations of other authors [27. 28]. This distribution is characterized by high values of tensile stresses in the reinforcement, fusion and heat affected zone. In the area of the parent material (outside the heat affected zone), in the upper part of the welded plate occur 
compressive stresses. They decrease linearly downwards so that at the lower part of the plate, then undergo into tensile stress of a small value.

\section{References}

[1] Fachinotti, V.D., Anca, A.A., Cardona, A.: Analytical solutions of the thermal field induced by moving double-ellipsoidal and double elliptical heat sources in a semi-infinite body. International Journal for Numerical Methods Biomedical Engineering, Vol. 27, pp. 595-607 (2011)

[2] Antonakakis, T., Maglioni, C., Vlachoudis, V.: Closed form solutions of the heat diffusion equation with Gaussian source. International Journal of Heat and Mass Transfer. Vol. 62, pp. 314-322 (2013)

[3] Ghosh, A., BarmaN, N., Chattopadhyaya, S., Hloch, S.: (2013) A study of thermal behaviour during submerged arc welding. Strojniški vestnik - Journal of Mechanical Engineering. Vol. 59, pp. 333-338 (2013)

[4] Franko, A., Romoli, L., Musacchio, A.: Modelling for predicting seam geometry in laser beam welding of stainless steel. International Journal of Thermal Sciences. Vol. 79, pp. 194-205 (2014)

[5] Salimi, S., Bahemmat, P., Haghpanahi, M.: A 3D transient analytical solution to the temperature field during dissimilar welding processes. International Journal of Mechanical Sciences. Vol. 79, pp. 66-74 (2014)

[6] Mahapatra, M.M., Datta, G.L., Pradhan, B.: Three-dimensional finite element analysis to predict the effects of shielded metal arc welding process parameters on temperature distributions and weldment zones in butt and one-sided fillet welds. Proceedings of the Institution of Mechanical Engineers - Proceedings of the Institution of Mechanical Engineers, Part B: Journal of Engineering Manufacture. Vol. 220, pp. 837-845 (2006)

[7] Kumar, A., T. DebRoy, T.: (2007) Heat transfer and fluid flow during gas-metal-arc fillet welding for various joint configurations and welding positions. Metallurgical and Materials Transactions. Vol. 38A, pp. 506-519 (2007)

[8] Wang, S., Goldak, J., Zhou, J., Tchernov, S., Dowey, D.: Simulation on the thermal cycle of a welding process by space-time convection-diffusion finite element analysis. International Journal of Thermal Scienses. Vol. 48, pp. 936-947 (2009)

[9] Lee, H.T., Chen, C.T., Wu, J.L.: 3D numerical study of effects of temperature field on sensitisation of Alloy 690 butt welds fabricated by gas tungsten arc welding and laser beam welding. Science and Technology of Welding and Joining. Vol. 15, pp. 605-612 (2010)

[10] Piekarska, W., Kubiak, M.: Three-dimensional model for numerical analysis of thermal phenomena in laser-arc hybrid welding process. International Journal of Heat and Mass Transfer. Vol. 54, pp. 4966-4974 (2011)

[11] Chen, Y., He, Y., Chen, H., Zhang, H., Che, S.: Effect of weave frequency and amplitude on temperature field in weaving welding process. International Journal of Advanced Manufacturing Technology. Vol. 75, pp. 803-813 (2014)

[12] Winczek J., Gawrońska E.: The modeling of heat affected zone (HAZ) in submerged arc welding (SAW) surfacing steel element. Metalurgija. Vol. 55(2), pp. 225 - 228 (2016)

[13] Winczek, J.: New approach to modeling of temperature field in surfaced steel elements. International Journal of Heat and Mass Transfer. Vol. 54, pp. $4702-4709$ (2011)

[14] Avrami, M.: Kinetics of phase change. I. General theory, Journal of Chemical Physics. Vol. 7, pp. 1103-1112 (1939)

[15] Piekarska, W., Kubiak, M., Saternus, Z.: Numerical simulation of thermal phenomena and phase transformations in laser-arc hybrid welded joints, Archives of Metallurgy and Materials. Vol. 56, pp. 409-421 (2011)

[16] Domański, T., Bokota A.: Numerical models of hardening phenomena of tools steel base on the TTT and CCT diagrams, Archives of Metallurgy and Materials. Vol. 56, pp. 325-344 (2011)

[17] Winczek, J.: The analysis of stress states in steel rods surfaced by welding. Archives of Metallurgy and Materials. Vol. 58, pp. 1243-1252 (2013) 
[18] Bokota, A., Parkitny, R.: Modelling of thermal, structural and mechanical phenomena in hardening processes of steel elements. In: Piela A. [ed.] Informatics in Metal Technology (Gliwice: Silesian Univ. Technol.), Chapter 7, pp. 257 - 298 (2003)

[19] Piekarska, W., Kubiak, M.: Theoretical investigation into heat transfer in laser-welded steel sheets. Journal of Thermal Analysis and Calorimetry. Vol. 10, pp. 159-166 (2012)

[20] Brózda, J., Pilarczyk, J., Zeman, M.: TTT-welding diagrams transformation of austenite. Śląsk, Katowice, Poland (1983)

[21] Winczek, J., Kulawik, A.: Dilatometric and hardness analysis of C45 steel tempering with different heating-up rates. Metalurgija. Vol. 51(1), pp. 9 - 12 (2012)

[22] Gawąd, J., Szeliga, D., Bator, A., Pidvysockyy, V., Pietrzyk, M.: Interpretation of the tensile test results interpretation based on two criterion optimization, In: Proc. 11. Conf. KomPlasTech, Informatics in Metal Technology, Zakopane, 11-14.01.2004, Akapit, Kraków, Poland, pp. 27-34 (2004)

[23] Vila Real, P.M.M., Cazeli, R., Simoes da Silva, L., Santiago, A., Piloto, P.: The effect of residual stresses in the lateral-torsional buckling of steel I-beams at elevated temperature. Journal of Constructional Steel Research. Vol. 60, pp. 783-793 (2004)

[24] Melander, M.: A computional and experimental investigation of induction and laser hardening. Linkoping Univeristy, Sweden, (1985)

[25] Lian, J., Jiang, Z., Liu, J.: Theoretical model for the tensile work hardening behaviour of dualphase steel. Materials Science and Engineering. Vol. A147, pp. 55 - 65 (1991)

[26] Kim, S.K., Kim, Y.M., Lim, Y.J., Kim N.J.: Relationship between yield ratio and the material constants of the swift equation. Metals and Materials International. Vol. 12(2), pp. 131-135 (2006)

[27] Chang, P.H., Teng, T.L.: Numerical and experimental investigations on the residual stresses of the butt-welded joints. Computational Materials Science. Vol. 29, pp. 511 -522 (2004)

[28] Jiang, W., Liu, Z., Gong, J.M., Tu, S.T.: Numerical simulation to study the effect of repair width on residual stresses of stainless steel clad plate, International Journal of Pressure Vessels and Piping. Vol. 87, pp. $457-463$ (2010) 